\title{
BMJ Open International variations in primary care physician consultation time: a systematic review of 67 countries
}

\author{
Greg Irving, ${ }_{1}^{1}$ Ana Luisa Neves, ${ }^{2,3}$ Hajira Dambha-Miller, ${ }^{1,4}$ Ai Oishi, ${ }^{5}$ \\ Hiroko Tagashira, ${ }^{6}$ Anistasiya Verho, ${ }^{7,8}$ John Holden $^{9}$
}

To cite: Irving G, Neves AL, Dambha-Miller $\mathrm{H}$, et al. International variations in primary care physician consultation time: a systematic review of 67 countries. BMJ Open 2017;7:e017902. doi:10.1136/ bmjopen-2017-017902

- Prepublication history and additional material for this paper are available online. To view please visit the journal (http:// dx.doi.org/10.1136/bmjopen2017-017902).

Received 25 May 2017

Revised 28 July 2017

Accepted 31 July 2017

\section{CrossMark}

${ }^{1}$ Primary Care Unit, University of Cambridge, Cambridge, UK ${ }^{2}$ Department of Community Medicine, Information and Health Decision Sciences (MEDCIDS), University of Porto, Porto, Portugal

${ }^{3}$ Centre for Health Policy, Institute Global Health

Innovation, Imperial College

London, London, UK

${ }^{4}$ Nuffield Department of Primary

Care Health Sciences, University of Oxford

${ }^{5}$ The Usher Institute of Population Health and Informatics, University of Edinburgh, Edinburgh, UK ${ }^{6}$ Horton General Hospital, Banbury, UK

${ }^{7}$ The University of Helsinki, Finland

${ }^{8}$ National Institutefor Health and Welfare (THL)

${ }^{9}$ Garswood Surgery, Wigan, UK

Correspondence to

Dr Greg Irving;

gi226@cam.ac.uk

\section{ABSTRACT}

Objective To describe the average primary care physician consultation length in economically developed and low-income/middle-income countries, and to examine the relationship between consultation length and organisational-level economic, and health outcomes. Design and outcome measures This is a systematic review of published and grey literature in English, Chinese, Japanese, Spanish, Portuguese and Russian languages from 1946 to 2016, for articles reporting on primary care physician consultation lengths. Data were extracted and analysed for quality, and linear regression models were constructed to examine the relationship between consultation length and health service outcomes.

Results One hundred and seventy nine studies were identified from 111 publications covering 28570712 consultations in 67 countries. Average consultation length differed across the world, ranging from $48 \mathrm{~s}$ in Bangladesh to $22.5 \mathrm{~min}$ in Sweden. We found that 18 countries representing about $50 \%$ of the global population spend 5 min or less with their primary care physicians. We also found significant associations between consultation length and healthcare spending per capita, admissions to hospital with ambulatory sensitive conditions such as diabetes, primary care physician density, physician efficiency and physician satisfaction.

Conclusion There are international variations in consultation length, and it is concerning that a large proportion of the global population have only a few minutes with their primary care physicians. Such a short consultation length is likely to adversely affect patient healthcare and physician workload and stress.

\section{BACKGROUND}

Primary care-driven health systems are effective at reducing disease, mortality and promoting a more equitable distribution of health worldwide. ${ }^{1}$ As the global population increases, the demand for primary care is also growing in both economically developed,low-income,middle-income countries. This is leading to an array of different consultation lengths, with concerns among primary care physicians worldwide about the impact of shorter consultations. ${ }^{2}$ A recent survey of primary care physicians in Australia,

\section{Strengths and limitations of this study}

As the demand for primary healthcare increases worldwide, the length of the consultation is also increasingly under pressure and there are concerns about the impact of less time with the physician.

- This is the largest international review of consultation length to date and includes six languages, 67 countries and 111 publications, which represent 28 million primary care consultations worldwide.

- Limitations of the review include the fact that differences between rural and urban, and public and private practices, were not taken into account, and the analyses rely on average consultation lengths.

- As with many comparisons of international data, the associations comparing consultation length with outcome data contained a relatively small number of data points.

Canada, France, Germany, the Netherlands, New Zealand, Norway, Sweden, the UK and the USA reported that over one-third of all primary care physicians are dissatisfied with the time available per patient. ${ }^{3}$ Surveys of primary care physicians suggest that shorter consultations compromise the care provided. ${ }^{4}$ For example, shorter consultation length can reduce the range of services provided in primary care. ${ }^{56}$ Meanwhile primary care phyisican stress scores are particularly high among slower doctors with high booking rates, with many reporting they often feel rushed at the end of the consultation. ${ }^{2}$

Average consultation length is also a quality indicator used by the WHO and the International Network for the Rational Use of Drugs (INRUD) to promote the safe and cost-effective use of drugs around the world. Several countries who follow the INRUD method for measuring consultation have set their own optimum consultation length as a quality standard. For example, Egypt recommends 30 min per patient as the optimum consultation length in primary care. ${ }^{7}$ Average consultation length is also used in the primary 
care monitoring tool as an outcome indicator. ${ }^{8}$ The monitoring tool suggests that at a system level change in consultation length depends on a range of other structural and process variables such as the number of primary care physicians. ${ }^{9}$ It is widely believed that longer consultations are better and that more primary care physicians will be required to give patients more time. ${ }^{1011}$ However, a Cochrane systematic review of clinical trials reported that there is insufficient evidence to say whether increasing consultation length provides patient benefit. ${ }^{12}$ The review did, however, highlight that there is some evidence to suggest that longer consultations improve health promotion, patient enablement and the quality of record keeping. Other reviews suggest that longer consultations lead to a more accurate diagnosis of mental health problems and that time pressures can be a major barrier to treating depression. ${ }^{13}$ There is also trial evidence that in patients with multimorbidity, longer consultations lead to an improved quality of life and patient enablement. ${ }^{1415}$

It is important that the methods used by researchers to measure consultation length are representative of the true consultation length, that is, the time that doctors and patients spend together. There is a need to accurately and precisely measure consultation length and avoid systematic errors. ${ }^{16}$ For those methods involving direct observation, researchers also need to consider how the different forms of reactivity will influence results, that is, whether knowing one is being measured affects performance, a 'Hawthorne effect'. ${ }^{17}$ To date, only awareness of video recording has been shown not to influence consultation length and is considered as a reference standard for direct observation. Indirect approaches such as simply calculating the length of session and dividing it by the number of patients seen often lead to overestimation of consultation length, for example by ignoring administrative work. $^{18}$

Yet in the face of increasing demand for primary care globally and the need for better outcomes, to date, there have been no comprehensive high-quality reviews that collate consultation lengths worldwide and examine how these relate to organisation-level economic and health outcomes. Such information remains vital if nations are to learn from each other. Previous reviews have been limited by focusing on a small number of countries, no assessment of the methods used to measure consultation length, and adopting unsystematic approaches or mixing primary and secondary care consultations. ${ }^{9}{ }^{19} 20$ The aim of this study was to undertake a systematic review of the literature to describe the average primary care physician consultation length on as wide a number of reports as we could find worldwide. We also identified methods used to measure consultation lengths, and examined the association between consultation length and organisational-level economic and health outcomes.

\section{METHODS}

We searched the following electronic databases from January 1946 to 2016: English language (Medline, Embase), Chinese (CNKI, Wanfang, VIP), Japanese (Ichushi), Russian (Yandex, Rambler), and Spanish and Portuguese (SciELO). The search strategy was based on the Medline search described by Wilson et al (excluding steps 24-34). Sample search strategy can be found in the online supplementary file 1 . Searches were supplemented by a survey of national members from the World Organization of National Colleges, Academies and Academic Associations of General Practitioners/Family Physicians (WONCA), who were asked to search the grey literature in their respective country for evidence relating to consultation length in either English or their native language. The grey literature search also included the WHO/ INRUD database (2000-2016) and Robert Graham data repository (2009-2016). One author (GI) screened all references and excluded duplicate records and those that were not eligible based on our selection criteria for considering studies. Two authors (GI and ALN) then applied the criteria to the short-listed references for fulltext screening.

\section{Study selection criteria}

We included observational studies including cross-sectional studies, surveys and cohorts of consultation length with primary care physicians. Primary care physicians were defined broadly as any medically qualified physician who provides primary care. Terms for primary care physicians differ according to different settings and include general practitioners (GPs), family doctors, family practitioners and other physicians working in primary healthcare settings and who perform primary healthcare task. ${ }^{12}$ Studies set in secondary care and randomised controlled trials were excluded.

\section{Data extraction}

One author (GI) extracted data into Excel based on study characteristics using the agreed criteria; this was then independently reviewed by another author (ALN) for consistency with disagreements resolved by discussion. Data were extracted based on the approach described by Wilson and Childs. ${ }^{9}$ This included location, duration, design, number of consultations measured, mean consultation length, method for measuring consultation length and approach to analysis. Publicly available data were used to calculate the mean consultation length for the National Ambulatory Medical Care Survey (NAMCS). Here only data related to 'General/family physicians' were included, and the mean consultation length was calculated using the 'timemd' variable in Stata V.13.1. ${ }^{21}$

\section{Quality assessment}

We assessed the quality of included studies independently using the National Heart, Lung and Blood Institute (NIH) quality assessment tool for observational studies. ${ }^{22}$ Where data were missing we attempted to contact the authors. 
We did not plan to conduct a subgroup analysis and did not conduct a subgroup analysis a posteriori. Survey data were only considered reliable if they had at least 30 unweighted records and a relative SE less than $30 \%$.

\section{Data synthesis}

Structural associations

Organisation-level rather than patient-level analysis was undertaken. Where there were at least 10 data points, trends in changes in average consultation length were described. Linear regression models were constructed to examine the association between average consultation length and (1) the number of primary care physicians per 1000 population, (2) per capita healthcare spending and (3) average consultation rate per patient per year. The data for determining the number of primary care doctors per 1000 came from the Organisation for Economic Co-operation and Development (OECD) healthcare data set and European Forum of Medical Associations membership survey. ${ }^{23}{ }^{24}$ Per capita healthcare spending data came from the World Bank, and the control variable was gross domestic product (GDP) per capita purchasing power parity in US dollar. Consultation rate came from the NIVEL primary care database. ${ }^{25}$ Consultation rate analyses were completed using Stata V.13.1. An association was termed significant if the $\mathrm{p}$ value was $<0.05$.

\section{Outcome associations}

Age-adjusted data on hospital admission for ambulatory sensitive conditions (diabetes, asthma and chronic obstructive pulmonary disease (COPD)) per 1000 population were taken from the WHO hospital morbidity database and were adjusted for disease prevalence, the availability of hospital beds, density of primary care physician and per capita health spending. Data on patients reporting spending enough time with their regular doctor were taken from OECD report on healthcare quality indicators and were adjusted for per capita health spending. Data on burnout among family doctors were taken from a publication by Soler et $a{ }^{26}{ }^{26}$ Chance of visiting an emergency department was taken from a publication by van den Berg $e t a l^{27}$ as part of the QALYCO-PC (Quality and Costs of Primary Care in Europe) study. Data for primary care doctors being somewhat or very dissatisfied with the time they spend with their patient were obtained from the Commonwealth Fund and were adjusted for per capita health spending. ${ }^{28}$ Data on the patients having an X-ray, ultrasound or other scans in the last 12 months were taken from the European Union Eurobarometer. ${ }^{29}$ An association was considered significant if the $p$ value was $<0.05$.

\section{RESULTS}

Initial searches identified 1016 records, of which 838 were excluded. We included 178 studies in 111 publications. Forty-three $(39 \%)$ of which were identified from the grey literature. The flow of information through our systematic review is shown in figure 1 . The earliest study was in 1952 in the UK. The largest study was that by Hobbs $e t a l^{30}$, which used a data set comprising 101818352 from consultations in 2007-2014. The country with the largest number of studies was the USA (26), followed by Australia (16) and the UK (16).

\section{Average length of primary care physician consultations}

The average consultation length was available in 67 different countries (table 1), covering over 28530712 consultations. Average consultation length varied from $48 \mathrm{~s}$ in Bangladesh to $22.5 \mathrm{~min}$ in Sweden figure 2). There were 15 countries with their most recently reported consultation length at $<5 \mathrm{~min}, 25$ countries with a consultation length of 5-9.9 min, 11 countries with 10-14.9 min, 13 countries with a consultation length of $15-19.9$ min and 3 countries with a consultation length of $\geq 20 \mathrm{~min}$. Three countries had sufficient data points to determine long-term trends: Australia, UK and USA. In Australia consultation length was relatively stable, in the USA consultation length was increasing (by $12 \mathrm{~s}$ a year), and in UK consultation length was increasing (by $4.2 \mathrm{~s}$ a year). These trends are shown graphically in figure 3 .

INRUD, International Network for the Rational Use of Drugs; SMS, short message service.

\section{Methods used to measure consultation length}

These were variable and included calculations based on electronic patient record data, estimates based on the length of session and number seen, physician surveys, observer with stopwatch, physician with stopwatch, audio tapes, video and short message service (SMS) text messages.

\section{Quality assessment}

The quality of studies was judged to be good in $40 \%$ of studies, fair in $36 \%$ and poor in $24 \%$. The most common reason for a poor rating was a failure to clearly define the outcome measures of consultation length to ensure this measure was valid, reliable and implemented consistently across all study participants.

\section{Structural associations}

There was a statistically significant relationship between consultation length and healthcare spending per capita $\left(\mathrm{p}=<0.001, \mathrm{R}^{2}=0.40\right.$; figure 4$)$. This remained significant after adjusting for GDP per capita purchasing power parity $\left(\mathrm{p}=<0.001, \mathrm{R}^{2}=0.37\right)$. There was no significant relationship between the consultation length and the number of consultations per patient per year $(\mathrm{p}=0.19$, $\mathrm{R}^{2}=0.14$ ). There was a statistically significant relationship between consultation length and the number of primary care physicians per 1000 population $(\mathrm{p}=<0.001$, $\mathrm{R}^{2}=0.21$; figure 5$)$. This remained significant after adjusting for per capita health spending $(\mathrm{p}=0.001$, $\left.\mathrm{R}^{2}=0.24\right)$. 


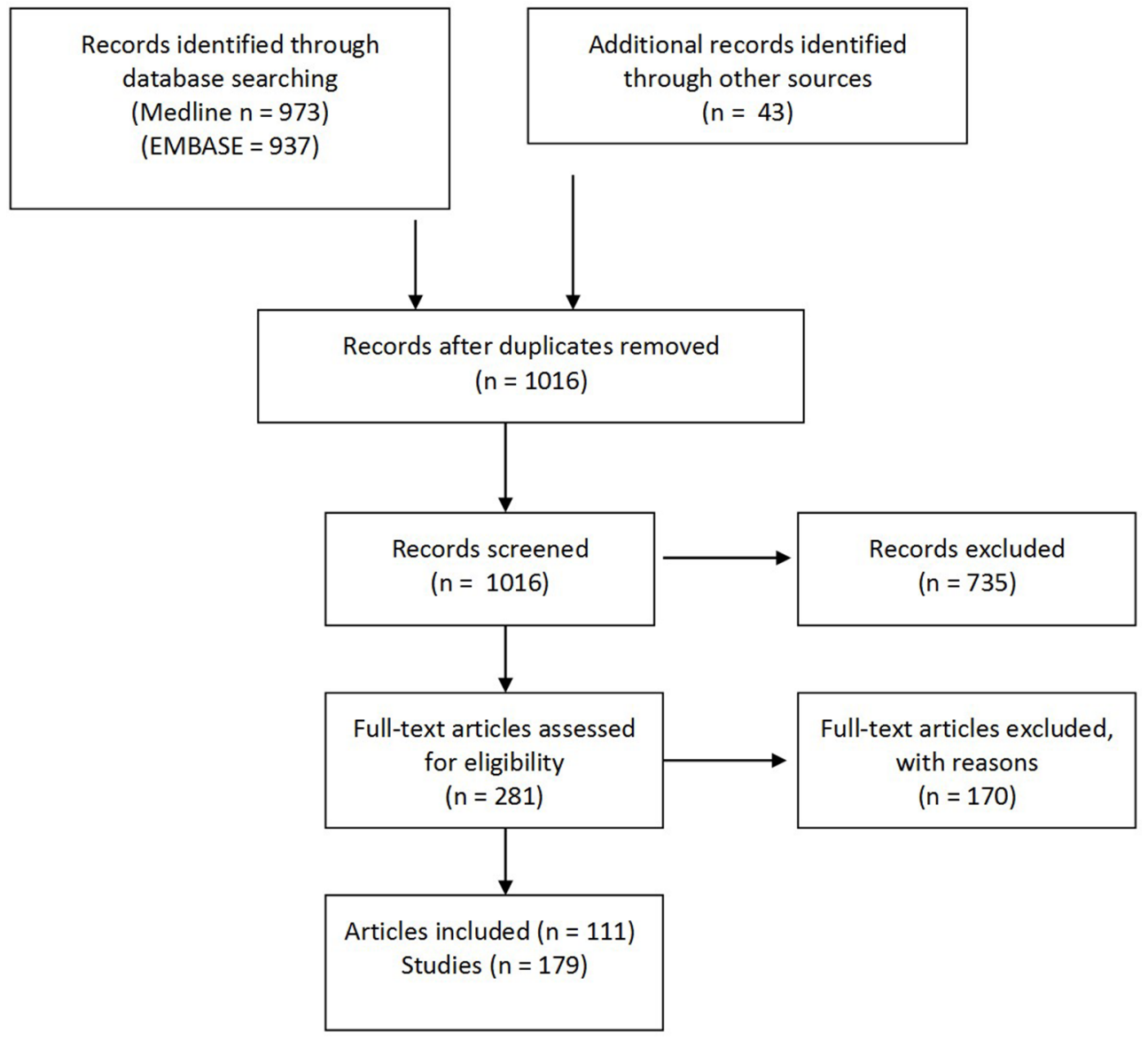

Figure 1 PRISMA flow diagram.

\section{Outcome associations}

There was a significant association between the consultation length and primary care physicians reporting being satisfied with consultation length after adjusting for health spending per capita $\left(p=0.04, R^{2}=0.80,7\right.$ observations). There was also a significant association with physician burnout relating to reduced personal accomplishment ( $\mathrm{p}=0.03, \mathrm{R}^{2}=0.99,5$ observations) but not emotional burnout $\left(\mathrm{p}=0.98, \mathrm{R}^{2}=0.14,5\right.$ observations) or depersonalisation $\left(\mathrm{p}=0.50, \mathrm{R}^{2}=0.84,5\right.$ observations) items after adjusting for physician density and average number of visits per patient per year. There was no significant association between the consultation length and the patients receiving an X-ray, ultrasound or other scan in the last 12 months $\left(\mathrm{p}=0.86, \mathrm{R}^{2}=0.001\right.$, 22 observations). There was statistically significant reduction in hospital admissions for diabetes $(\mathrm{p}=0.04$, $\mathrm{R}^{2}=0.27,23$ observations) but not asthma ( $\mathrm{p}=0.30$, $\mathrm{R}^{2}=0.17$, 16 observations) or COPD $\left(\mathrm{p}=0.35, \mathrm{R}^{2}=0.22\right.$, 11 observations). There was no significant relationship between consultation length and accident and emergency $(\mathrm{A}+\mathrm{E})$ department attendance $\left(\mathrm{p}=0.75, \mathrm{R}^{2}=0.01\right.$, 22 observations). There was no significant association between average consultation length and patient satisfaction with consultation length after adjusting for per capita health spending and physician density $(\mathrm{p}=0.09$, $\mathrm{R}^{2}=0.86,7$ observations).

\section{DISCUSSION}

\section{Main findings and comparison to the literature}

This review demonstrates that consultation length of primary care physicians varies markedly across the world. It is concerning that 18 countries covering $~ 50 \%$ of the world's population have a latest reported mean consultation length of $5 \mathrm{~min}$ or less. Such a short consultation length is likely to adversely affect patient care and the workload and stress of the consulting physician. The reasons for such striking differences may reflect a number of factors, including issues relating to governance, workforce, access, continuity, comprehensiveness and coordination. For example, in countries such as Pakistan, Bangladesh and China, there is no appointment system, and individual primary care physicians may undertake over 90 consultations a day with a considerable amount of time taken up providing repeat prescriptions..$^{1031-33}$

Many of the studies included in this review also found that short consultation length was responsible for driving polypharmacy, overuse of antibiotics and poor communication with patients. ${ }^{1132} 34$ This supports the argument that there is a practical limit to how short a consultation can be for routine appointments. Little can be achieved in less than $5 \mathrm{~min}$ unless the focus is largely on the detection and management of gross disease. An average of 5 min may be the limit below which consultations amount to little more than triage and the issue of prescriptions. 


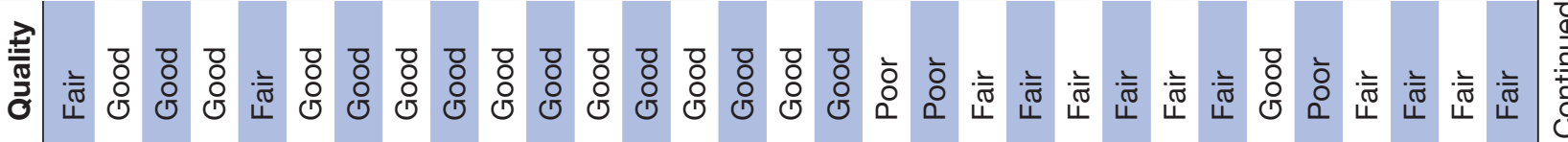

三
0
0
0
$\bar{t}$
$\frac{ \pm}{5}$
0
0
0
0

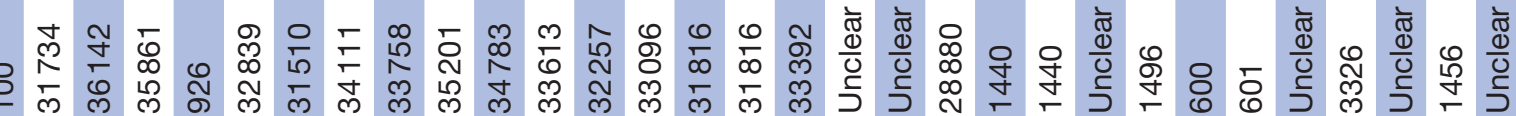

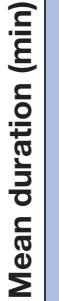

๓ (1)

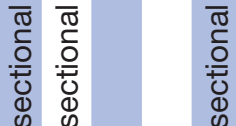

ब.

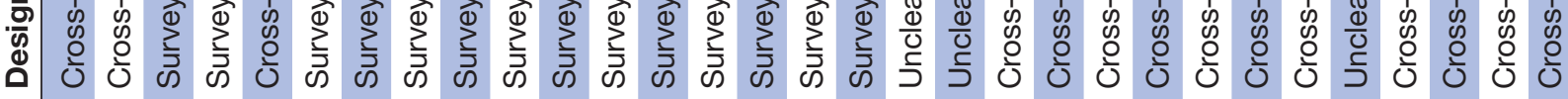

욜

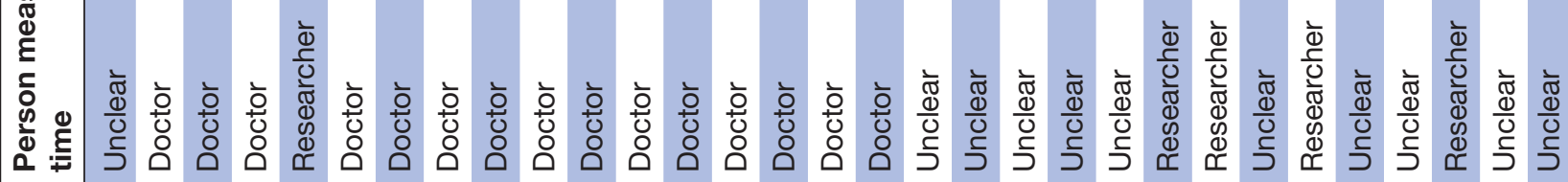
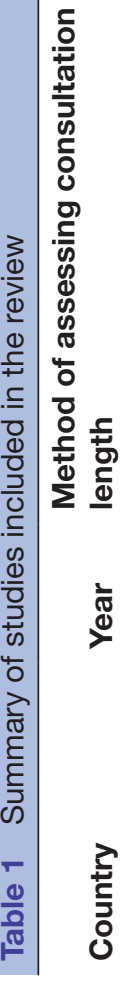

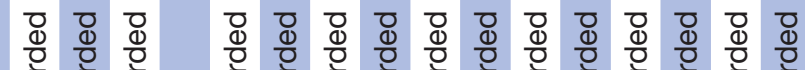

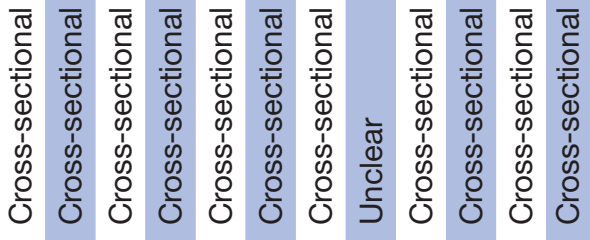

吾

衣

S 0.0

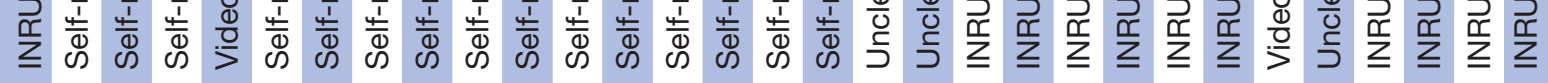

㐫

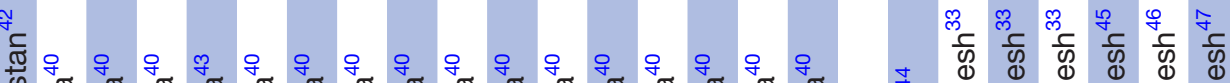

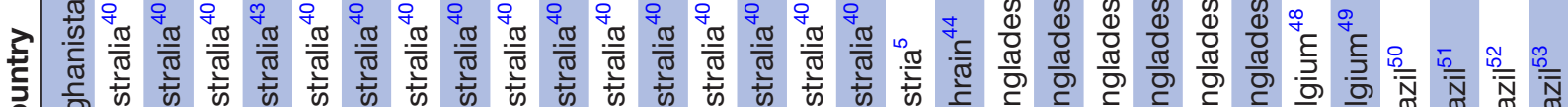
产 


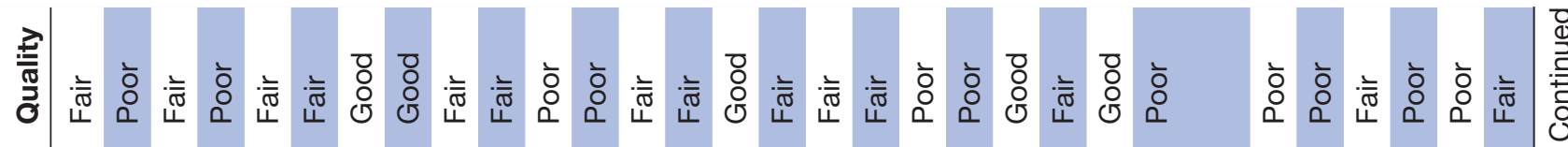

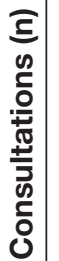

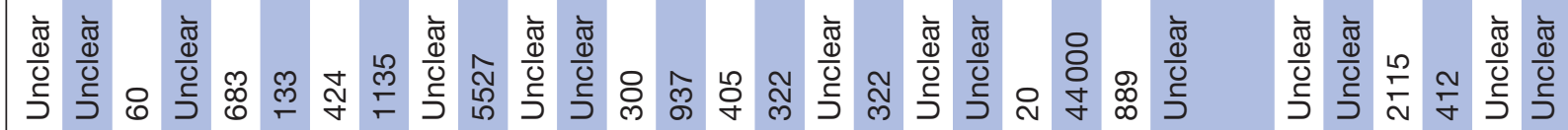

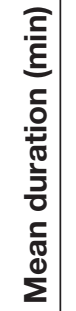

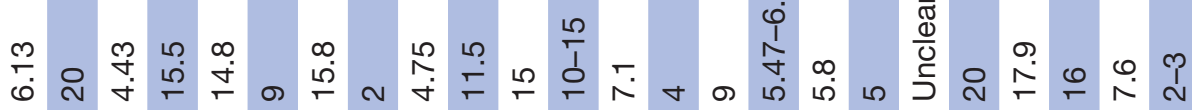

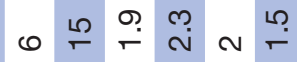

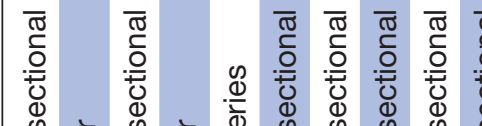

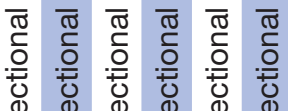

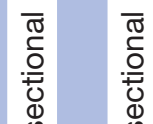

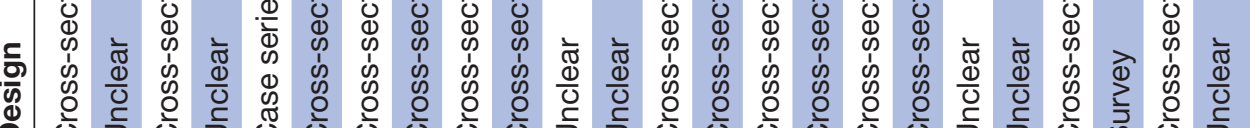

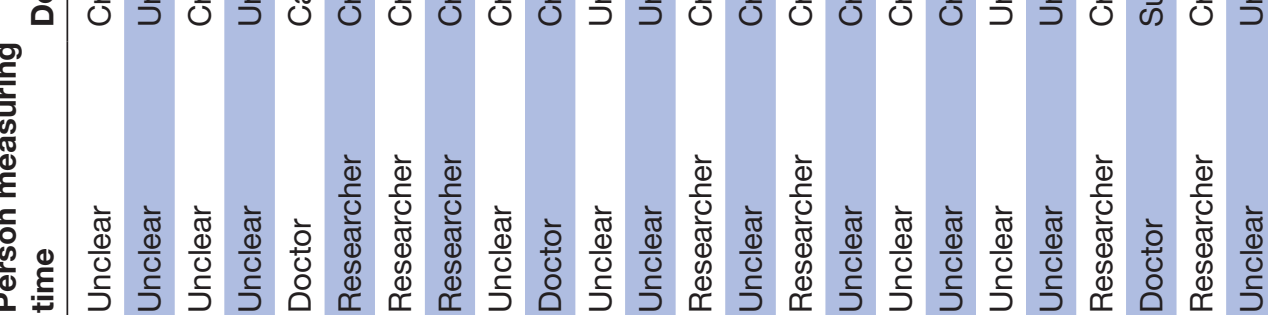

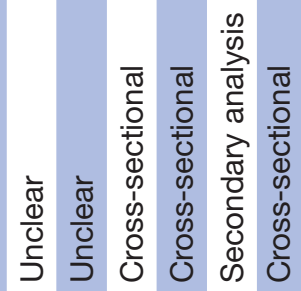

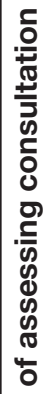

๘

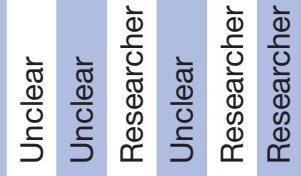

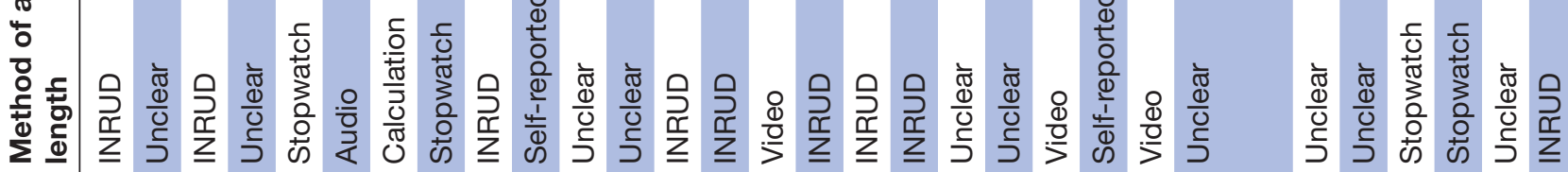

穴

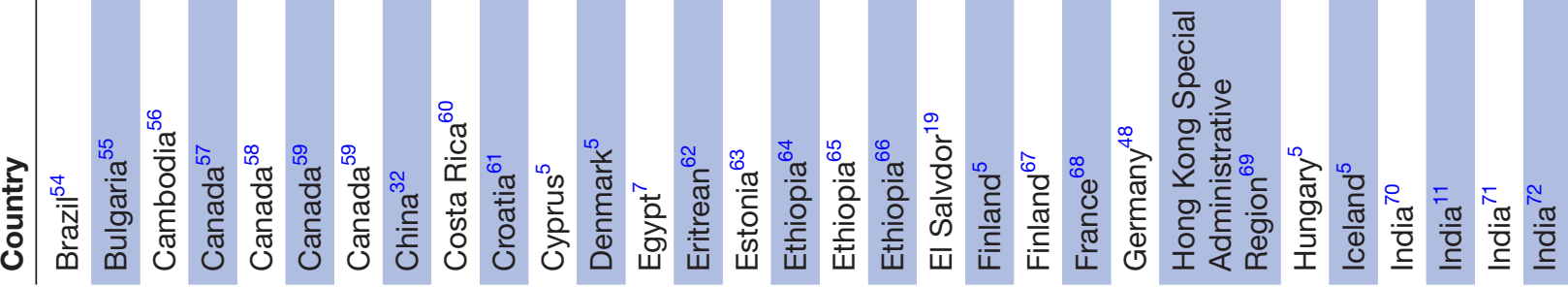


离

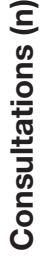

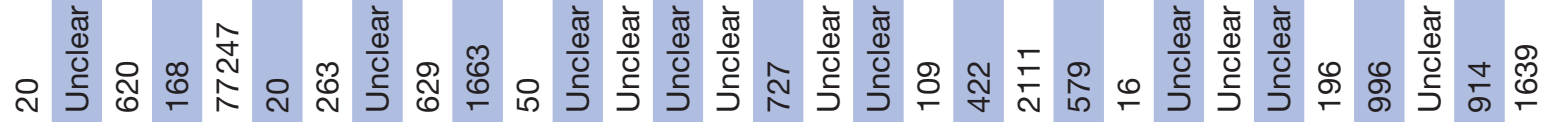

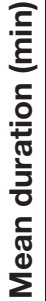

이 이

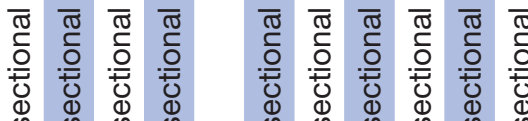

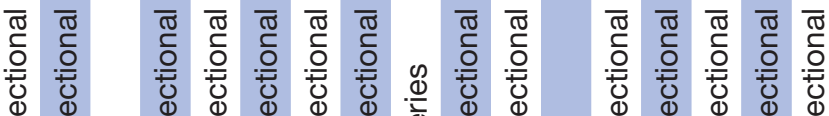

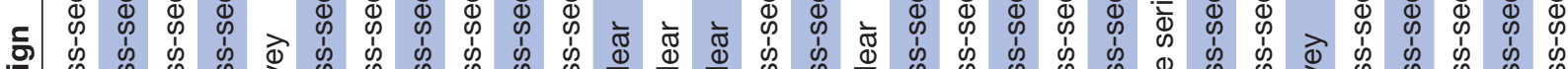

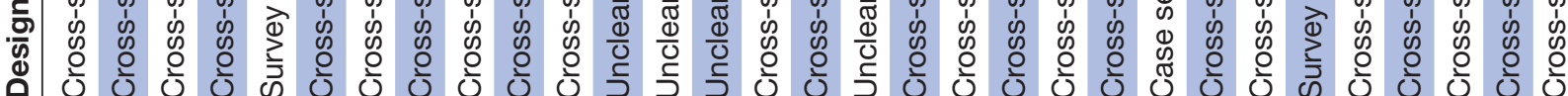

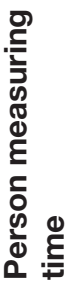

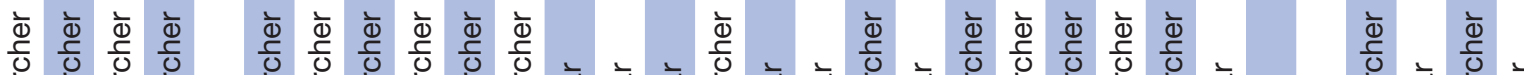

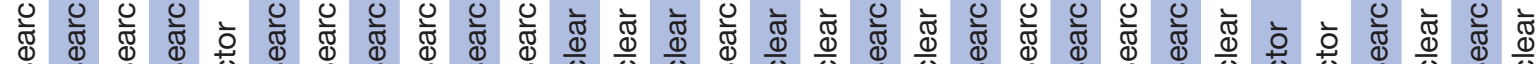

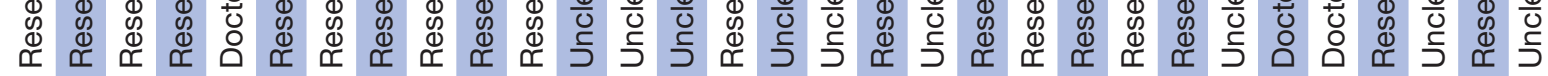

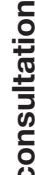

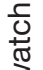

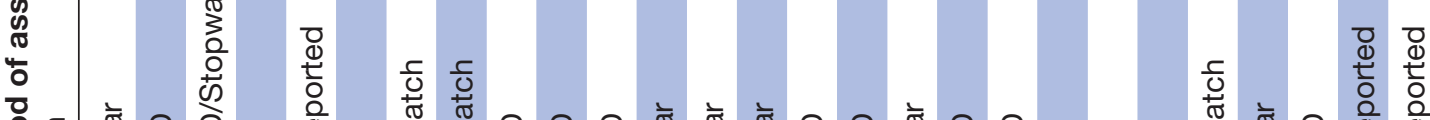

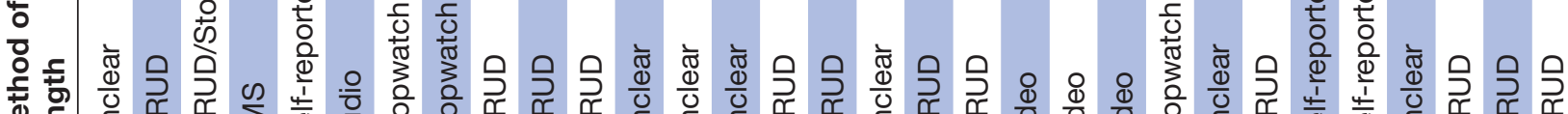

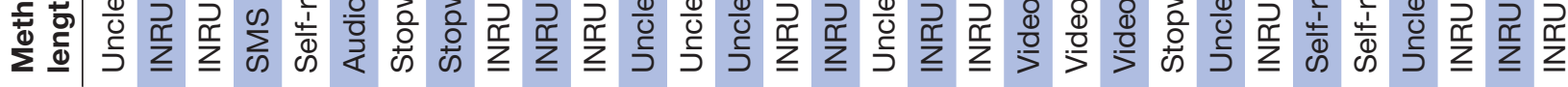

㐫

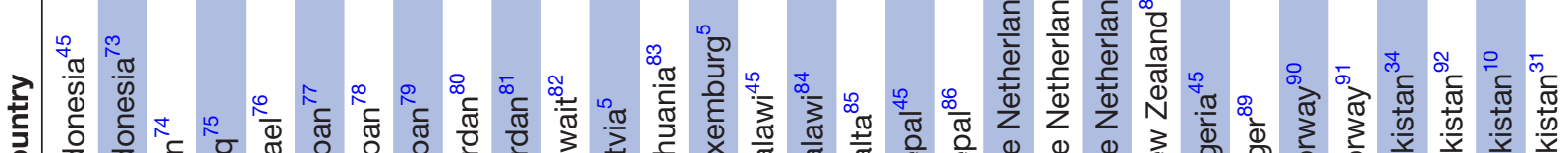




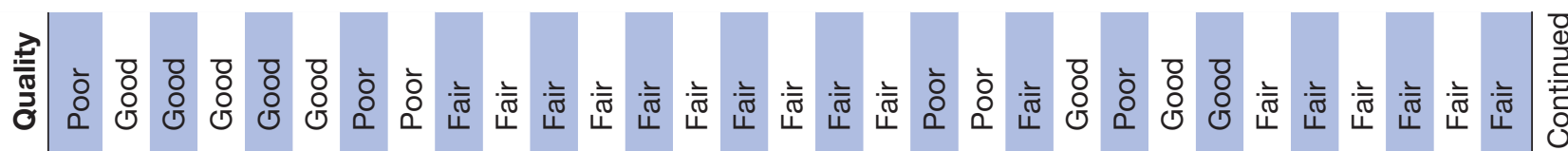

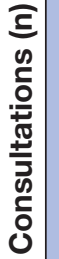

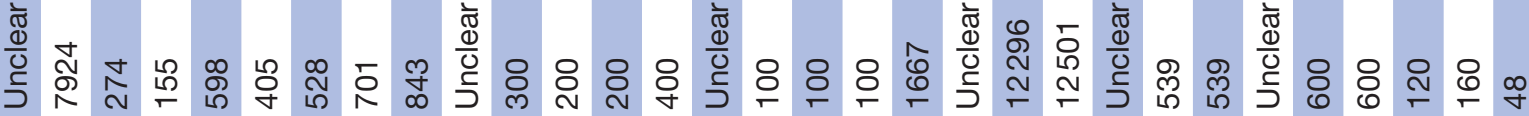

產

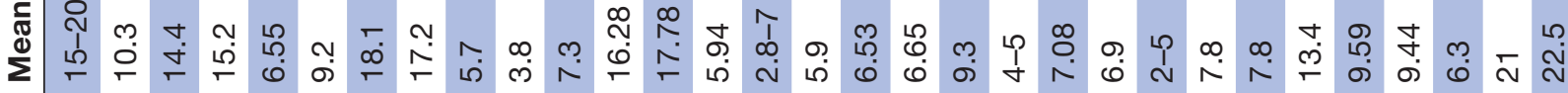

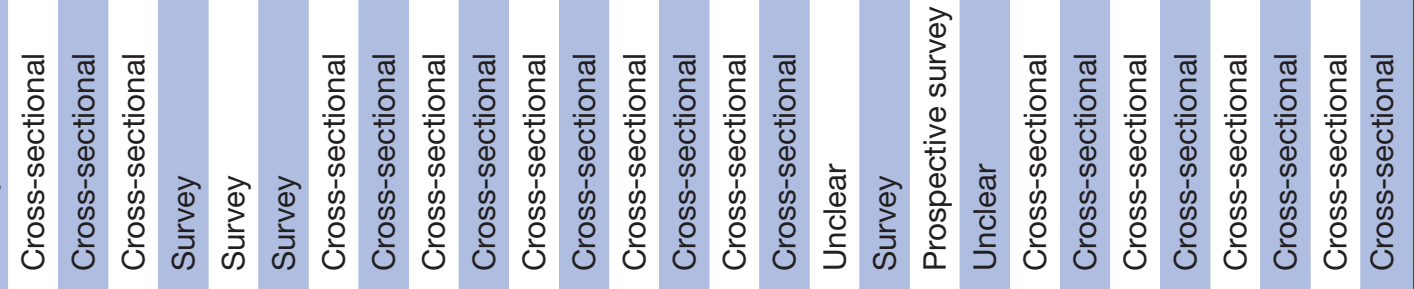

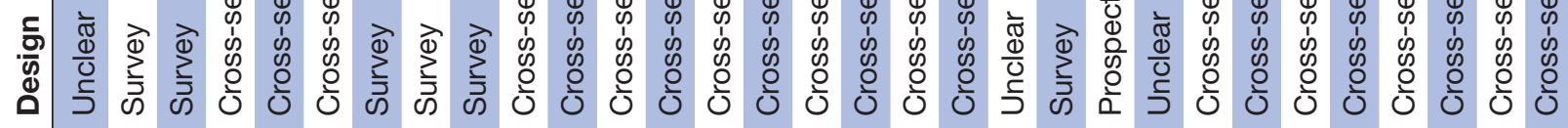

$\stackrel{\text { D }}{\stackrel{2}{=}}$

$\overrightarrow{\frac{\pi}{0}}$

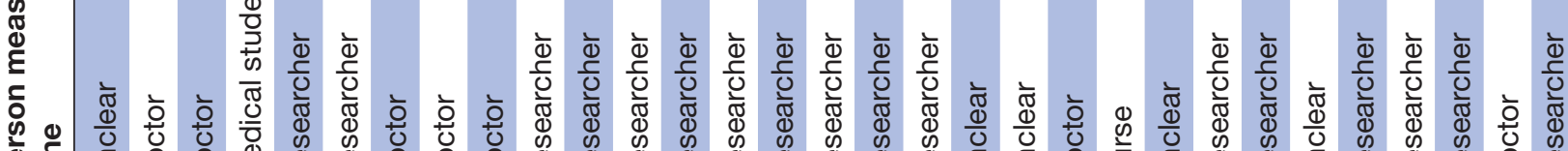

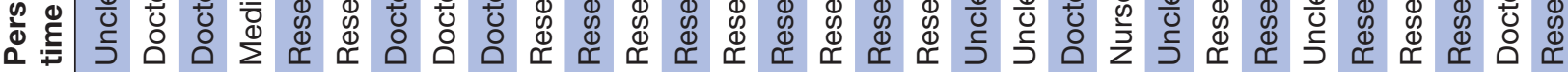

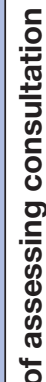

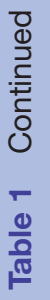

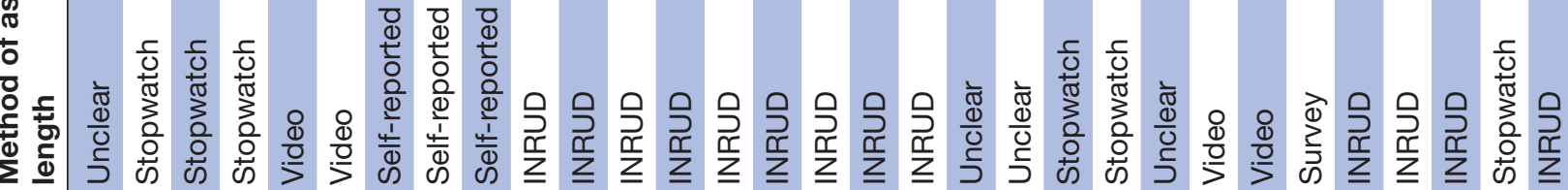

㐫

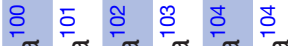

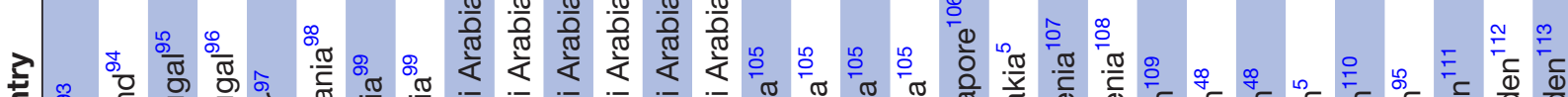

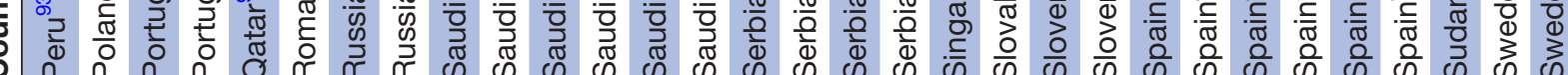

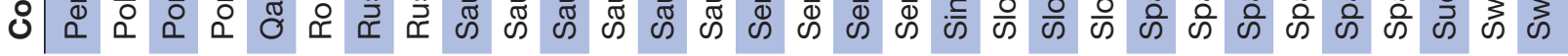




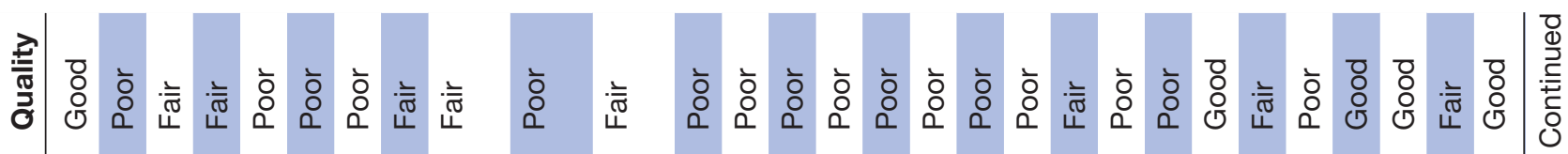

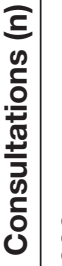

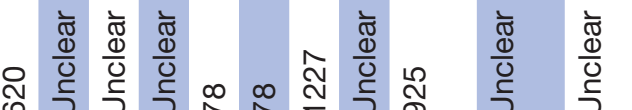

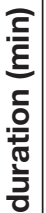

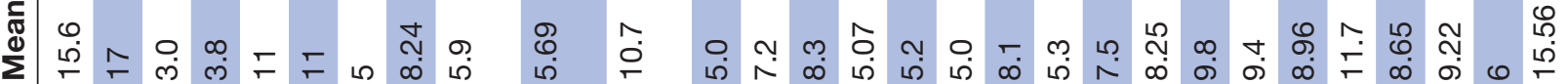

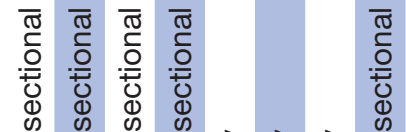

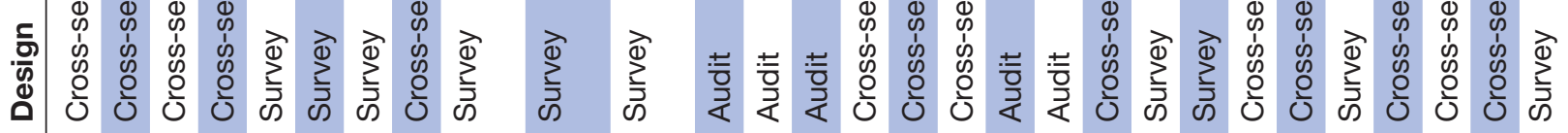

$\stackrel{\text { : }}{\stackrel{2}{2}}$

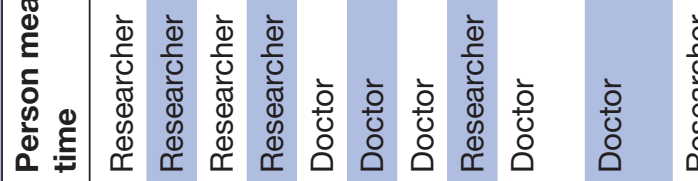

$\frac{\bar{d}}{\overline{0}}$

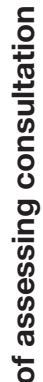

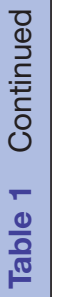

㐫

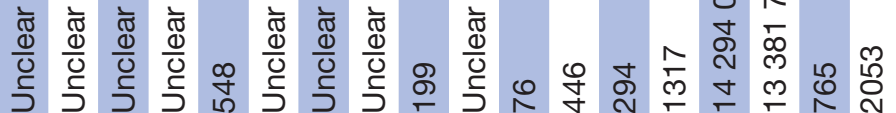

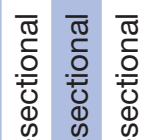

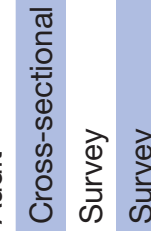
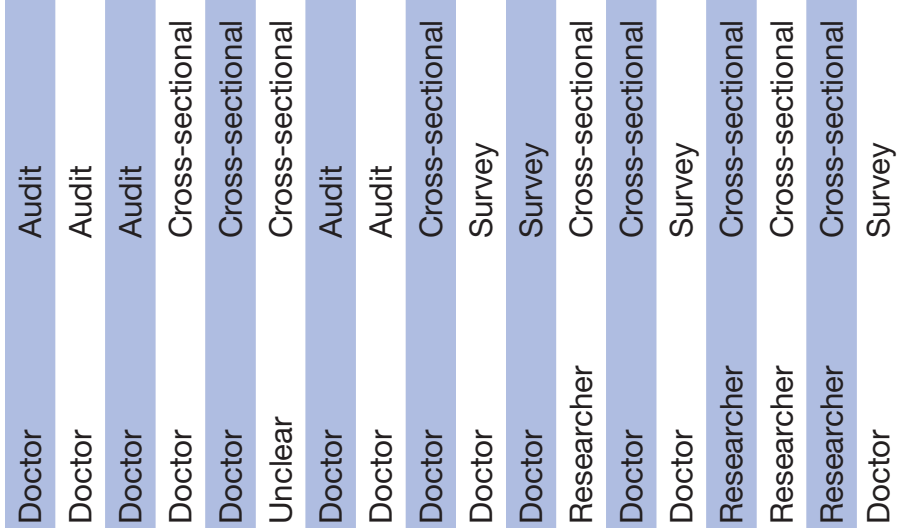

$\stackrel{\vec{\nabla}}{\stackrel{9}{+}}$

$\frac{\overline{0}}{\frac{0}{0}}$

용

क

○

$\vec{\omega}$

홍.

$\stackrel{\text { D }}{\stackrel{9}{2}}$

온

ì

¿̊ำ

잉

$z_{0}^{\infty}$

$\stackrel{\$ 1}{3}$

N

品

言

ळ్

$\stackrel{2}{\overrightarrow{0}}$

골

혹

긍.

훙.

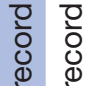

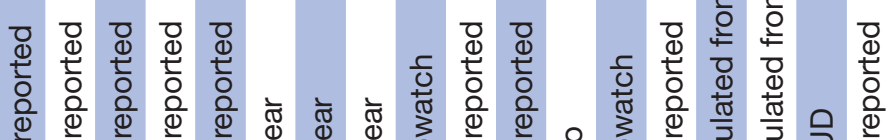

ह 등

웜

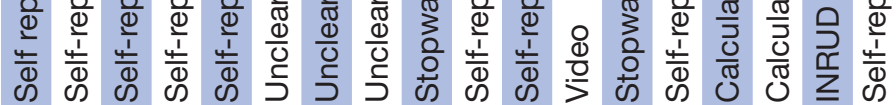




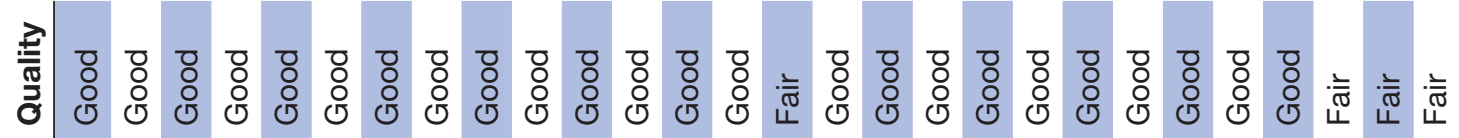

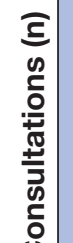

○

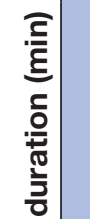

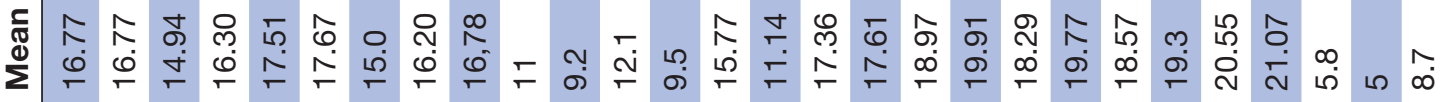

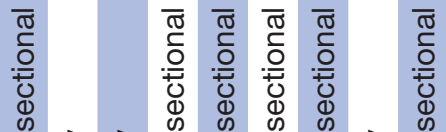

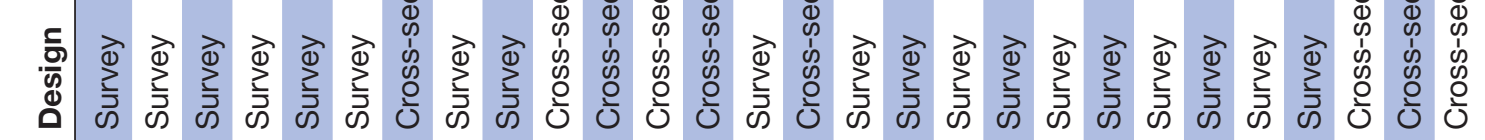

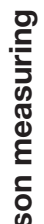

क人

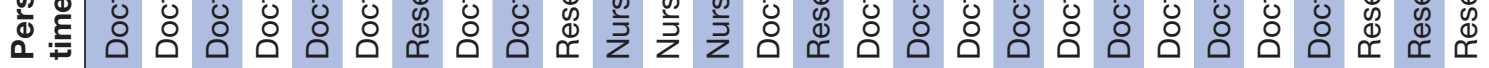

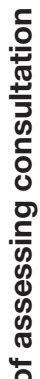

ঠ্ঠ 


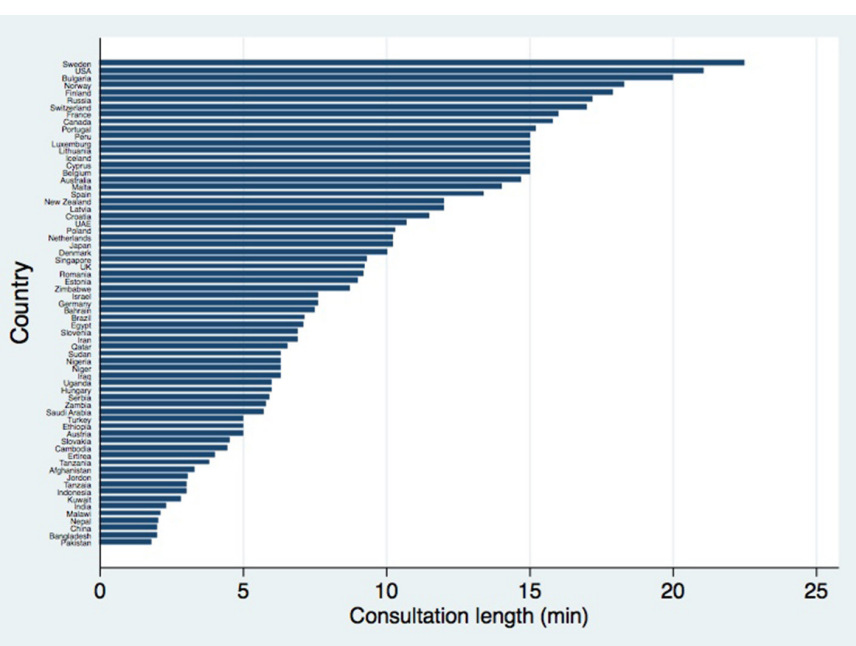

Figure 2 Average consultation length in each country based on most recent data.

A lack of time in the consultation is a key constraint to delivering expert generalist care. ${ }^{35}$ The finding of the association between shorter consultations and physician burnout due to a lack of personal accomplishment may indicate that doctors feel less productive and competent at managing complex multimorbid patients in those settings with short consultation lengths. Addressing this limitation is necessary if patients with complex needs and multimorbidity are to be effectively managed within primary care. ${ }^{36}$

There were considerable differences in the trends of consultation length over time between the USA, Australia and the UK. In USA the average consultation length has increased steadily to over 20 min-this despite the countries having a relatively stable proportion of primary care physicians per 1000 population. Consultation length in the UK has also increased steadily over time, although the methods used in the included studies were heterogeneous. Changes here predate the introduction of the quality standard of $10 \mathrm{~min}$ for routine booked appointments and
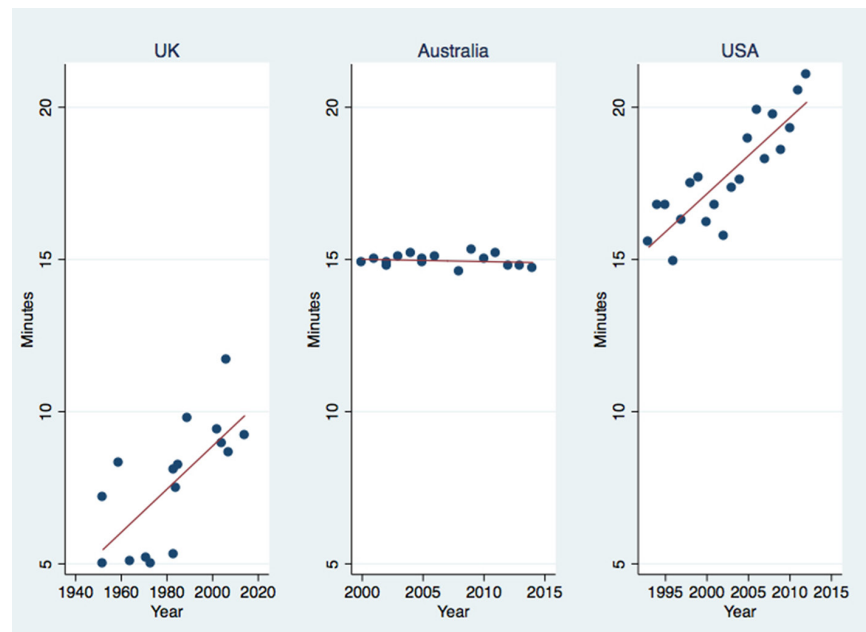

Figure 3 Consultation length over time in Australia, the USA and the UK.

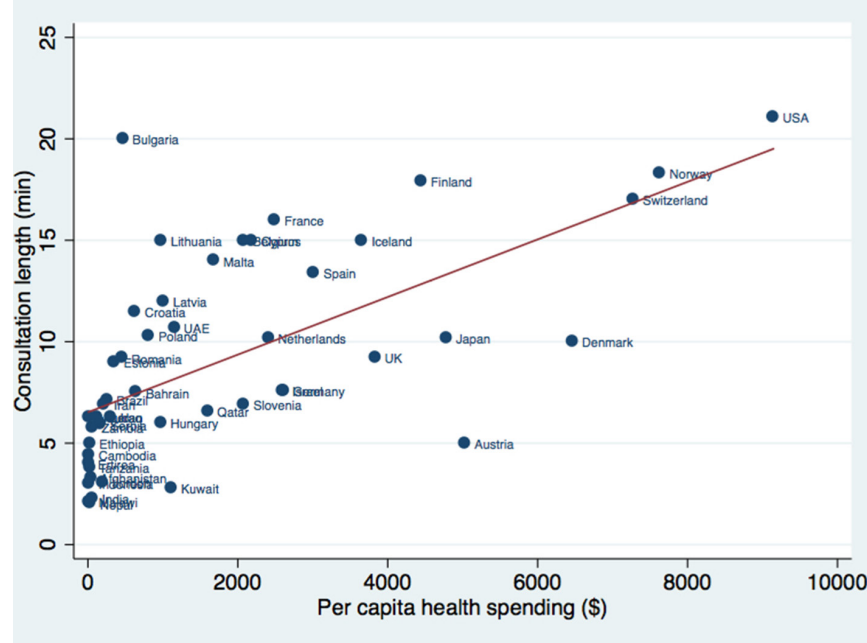

Figure 4 Consultation length versus per capita health spending (\$).

reflect the low starting point of consultation length and a steady increase in the density of primary care physicians over time. ${ }^{37}$ It is also interesting to note that at the current rate of change, the consultation length in the UK would only reach $15 \mathrm{~min}$ in 2086. Consultation length in Australia was stable at just under $15 \mathrm{~min}$, reflecting the popular book length of $15 \mathrm{~min}$, which avoids the increased charge for $20 \mathrm{~min}$ appointments.

The countries with the greatest health needs would be expected to have the greatest need for longer consultations, but their consultation lengths were generally low. The association between average consultation length and per capita healthcare spending supports the claims that shorter consultation length is a good measure of poverty, even in the industrialised world. While this association does not necessarily imply causation, it does suggests that the inverse care law may be an international phenomena. It was concerning that in some low-income/middle-income countries, average consultation length appeared to be shortening, suggesting that progress is not inevitable,

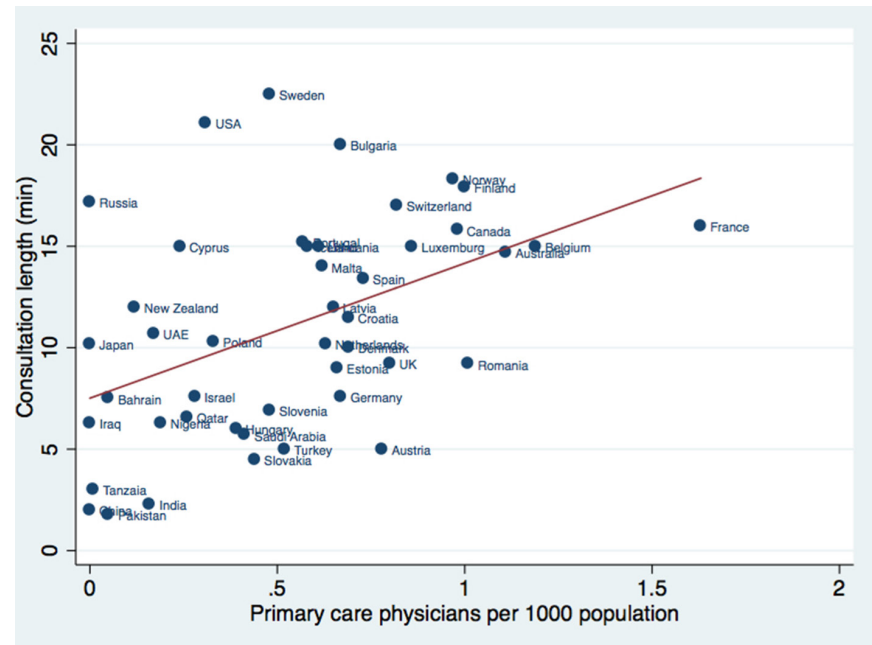

Figure 5 Average consultation length versus primary care physician density per 1000 population. 
and if resources are not put into primary care then expanding populations and rising treatment possibilities could overwhelm us.

The absence of a statistically significant relationship between consultation length and consultation rate per patient per year suggests that if the consultation length increases, it does not necessarily follow that the number of visits per year will decrease. The number of consultations per patient per year can vary widely from country to country, and the total time a patient spends with their primary care physician is also likely to vary widely. ${ }^{38}$ For example, in 2008 it was estimated that the mean number of consultations with a GP in the UK was 3.23 per year, and the average consultation length was $11.7 \mathrm{~min}$ so the total time spent with any GP per year was estimated to be $37.8 \mathrm{~min}$ per patient. In 1997 the total time was $27.8 \mathrm{~min}$, a 10 min increase in 11 years. ${ }^{38}$

Large variations in the number of primary care physicians per capita are known to exist between countries. ${ }^{24}$ The review found a statistically significant association between average consultation length and the number of primary care physicians per capita. This remained significant after adjusting for per capita healthcare spending. The USA appeared to be an outlier in this relationship, achieving a relatively long consultation length with only a modest primary care physician density—-this may be due to the ready availability of specialists in this country.

The association between consultation length and the burnout of primary physicians supports findings from national studies. ${ }^{4}$ Specifically, the association items relating to efficiency support reports thatincreasing workload may be a key contributing factor to burnout. .$^{26}$ There was an association identified between longer consultation length and reduced hospital admission for diabetes. This reflects findings elsewhere that strong primary care can reduce admissions for ambulatory sensitive conditions. ${ }^{5}$ The lack of association between consultation length and the requesting of scans support findings from other studies that long consultations do not necessarily result in more test requests. ${ }^{12}$ There was no association between $\mathrm{A}+\mathrm{E}$ admission rates; however, these data were not adjusted for ambulatory sensitive conditions.

\section{Quality of the evidence}

The quality of studies was graded 'good' in less than half of the included studies. Of the included studies $43 \%$ were identified in the grey literature and not published in peer-reviewed journals. Fifty studies had links to the WHO/INRUD, which includes average consultation length as a quality indicator for rational prescribing. Many studies failed to provide a definition of consultation length, leading to uncertainty as to what was actually measured. Despite evidence to show that awareness of video recording does not alter consultation length, relatively few studies followed this approach. ${ }^{18}$ The use of other techniques such as self-timing, observer timing with a stopwatch or by sending an SMS message is likely to be influenced by various forms of reactivity, changing one's behaviour when it is known one is being observed.

Although the response rate was satisfactory in some surveys, others had a high proportion of missing values for consultation length items. For example the NAMCS survey had $\sim 26 \%$ missing. Samples were often non-random or quasi-randomised and clustering effects were likely. Several studies had a sample size of less than 30 and as a result are likely to be unreliable. Self-reporting is likely to result in reporting bias. Inspection of data sets indicated that reporting in surveys tended to round to the nearest $5 \mathrm{~min}$ (or an even number). Calculating consultation length by dividing the total session by the number of patients seen is likely to lead to overestimation. ${ }^{16}$

Populations were poorly described in many studies. Gender of the consulting doctor, age of the doctor, country of graduation, qualification, location of practice (rural or urban), socioeconomic status, services provided, and proportion of chronic disease management, proportions of children, number of largely administrative consultations for example, and consultations principally used to issue repeat prescriptions are all known to influence consultation length, yet were seldom reported. Key summary statistics such as mean, median, mode, SD and 95\% CIs were inconsistently reported in the many of the poorer quality studies.

\section{Strengths and weaknesses}

This is the largest international review of consultation length to date. The search used English-language studies, and Chinese, Japanese, Spanish, Portuguese and Russian databases. Several of the identified studies were found in the grey literature from the survey of WONCA representatives. It is important to highlight that the findings presented here are intended to be illustrative. No weights were added to sample data to produce national estimates or to accurately assess the sampling error for consultation length. Given that many of the analyses use average consultation length rather than original data, the variance will be suppressed. As with many comparisons of international data, the associations comparing consultation length with outcome data contained a relatively small number of data points and are likely to be underpowered, running the risk of a type I error. ${ }^{39}$ Differences between rural and urban, and public and private practices, were not taken into account, which could explain some of the variations identified.

\section{Implications for research}

The Australian BEACH (Bettering the Evaluation and Care of Health) system is an excellent example of a consistently high-quality reporting of key summary statistics, including a large sample size, and a standardised method for collecting data that enabled annual comparisons. ${ }^{40}$ Unfortunately the Canadian physician survey missed opportunities to collect consultation length data, along with the UK where reporting has been infrequent and inconsistently measured. The American NAMCS 
was another good example of an open approach to sharing anonymised data on consultation length. ${ }^{41}$ It was concerning that data were only available for the remaining countries where the remaining $24 \%$ of the world population live. It is vital that organisations such as the OECD, WHO and WONCA encourage measurement of consultation length and rates in countries that currently have no data. At present this is reported by the WHO/World Bank only in relation to all doctors. These data should be disaggregated further to evaluate primary care physicians. Novel approaches to measuring consultation length, for example, SMS, hold promise, but the accuracy of such approaches needs to be validated against the reference standard of video consultations and evaluated to see if awareness of their use influences physicians' consultation length.

\section{Implications for policy}

Policy makers can compare their country with others to consider both what a desirable and mean consultation length should be, and also how administrative requirements can greatly influence how scarce time is spent when patients consult physicians. The very short consultation length in some countries contrasts markedly with the effort and expense used in reaching the facility. Instead of simply calling for longer consultation lengths, the focus should be on precisely how longer consultations can be achieved considering systems that have achieved this goal. Increasing the number of primary care physicians is likely to help the situation in many countries.

Average time is an established measure of quality and used by the WHO and the INRUD as a measure to promote the safe and cost-effective use of drugs-it should be universally and regularly reported and over time be accepted as an essential measure on the quality of health services around the world. Those countries with sufficient resources should consider adopting an approach similar to the Australian BEACH studies, which in our view represents the gold standard for consistent reporting.

\section{CONCLUSION}

There are international variations in consultation length, and it is concerning that a large proportion of the global population have only a few minutes with their primary care physicians. Such a short consultation length is likely to adversely affect patient healthcare and physician workload and stress.

Acknowledgements We would like to thank Kathy Holloway of the WHO for providing data from the INRUD database. We would also like to thank WONCA members for helping with the grey literature search. Special thanks also goes to Luisa Pettigrew (WONCA Executive and WHO liaison), Ryuki Kassai (Fukushima University), Faisal Al Nasir (Arabian Gulf University) and Shlomo Vinker (Tel Aviv University). We would also like to thank Jean Soler and the members of the European Burnout Study for sharing their data, and Michael van den Berg for sharing data on emergency department use.

Contributors Gl designed the review, extracted data, wrote the protocol, conducted the analysis, and drafted and revised the paper. ALN extracted data, and drafted and revised the paper. HD-M revised the paper. A0 extracted data. HT extracted data. AV extracted data. JH designed the review, and drafted and revised the paper. $\mathrm{Gl}$ is guarantor.

Funding GI is an NIHR Clinical Lecturer and HDM is an NIHR Doctoral Research Fellow who are funded by the National Institute for Health Research (NIHR). The views expressed are those of the author(s) and not necessarily those of the NHS, the NIHR, or the Department of Health. However, this research received no specific grant from any funding agency in the public,commercial, or not-for-profit sectors.

Competing interests None declared.

Provenance and peer review Not commissioned; externally peer reviewed.

Data sharing statement No additional data are available.

Open Access This is an Open Access article distributed in accordance with the Creative Commons Attribution Non Commercial (CC BY-NC 4.0) license, which permits others to distribute, remix, adapt, build upon this work non-commercially, and license their derivative works on different terms, provided the original work is properly cited and the use is non-commercial. See: http://creativecommons.org/ licenses/by-nc/4.0/

(c) Article author(s) (or their employer(s) unless otherwise stated in the text of the article) 2017. All rights reserved. No commercial use is permitted unless otherwise expressly granted.

\section{REFERENCES}

1. Starfield B, Shi L, Macinko J. Contribution of primary care to health systems and health. Milbank Q 2005;83:457-502.

2. Wilson $A$, McDonald $P$, Hayes $L$, et al. Longer booking intervals in general practice: effects on doctors' stress and arousal. $\mathrm{Br} J \mathrm{Gen}$ Pract 1991;41:184-7.

3. Osborn R, Moulds D, Schneider EC, et al. Primary care physicians in ten countries report challenges caring for patients with complex health needs. Health Aff 2015;34:2104-12.

4. Mercer SW, Hasegawa H, Reilly D, et al. Length of consultations. Time and stress are limiting holistic care in Scotland. BMJ 2002;325:1241.

5. Kringos DS. De sterkte van de eerste lijn in Europa, 2012.

6. Mercer SW, Fitzpatrick B, Gourlay G, et al. More time for complex consultations in a high-deprivation practice is associated with increased patient enablement. Br J Gen Pract 2007;57:960-6 http:// bjgp.org/content/57/545/960

7. Akl OA, El Mahalli AA, Elkahky AA, et al. WHO/INRUD drug use indicators at primary healthcare centers in Alexandria, Egypt. J Taibah Univ Med Sci 2014;9:54-64.

8. Kringos D, Boerma W, Bourgueil Y, et al. The strength of primary care in Europe: an international comparative study. Br J Gen Pract 2013;63:742-50.

9. Wilson A, Childs $S$. The relationship between consultation length, process and outcomes in general practice: a systematic review. Br J Gen Pract 2002;52:1012-20 http://www.ncbi.nlm.nih.gov/ pubmed/12528590

10. Prescription and Dispensing Practices in Public Sector Health Facilities in Pakistan: Survey Report.

11. Chattopadhyay A, Mondal T, Saha T, et al. An audit of prescribing practices in CGHS dispensaries of Kolkata. India, 2013.

12. Wilson $A D$, Childs $S$. Effects of interventions aimed at changing the length of primary care physicians' consultation. Cochrane database Syst Rev 2006:CD003540.

13. Hutton C, Gunn J, et al. Do longer consultations improve the management of psychological problems in general practice? A systematic literature review. BMC Health Serv Res 2007;7:71.

14. Mercer SW, Fitzpatrick B, Guthrie B, et al. The CARE Plus study - a whole-system intervention to improve quality of life of primary care patients with multimorbidity in areas of high socioeconomic deprivation: exploratory cluster randomised controlled trial and cost-utility analysis. BMC Med 2016;14:88.

15. Mercer SW, Watt GCM. The inverse care law: clinical primary care encounters in deprived and affluent areas of Scotland. Ann Fam Med 2007;5:503-10.

16. McWhinney IR, Stewart M. Innovative consultation time as a common European currency. Eur J Gen Pract 1995;1:175.

17. Holden JD. Hawthorne effects and research into professional practice. J Eval Clin Pract 2001;7:65-70.

18. Pringle M, Stewart-Evans $C$. Does awareness of being video recorded affect doctors' consultation behaviour? Br J Gen Pract 1990;40:455-8. 
19. Outomuro $D$, Actis $A M$. Analysis of ambulatory consultation length in medical clinics]. Rev médica Chile 2013;141:361-6.

20. World Health Organization. The World Medicines Situation: Chapter 8. Rational use of medicines. Geneva, 2004:75-92.

21. StataCorp. Stata Statistical Software: Release 13. College Station, TX: StataCorp LP, 2013.

22. NIH Quality Assessment Tool for Observational Cohort and CrossSectional Studies. https://www.nhlbi.nih.gov/health-pro/guidelines/ in-develop/cardiovascular-risk-reduction/tools/cohort (accessed 6 July 2017).

23. European Forum of Medical Associations and WHO. http://www. efma-forum.com/index.php/efma-members/national-medicalassociations (accessed 6 July 2017).

24. OECD Health Care Resources. https://stats.oecd.org/lndex.aspx? DataSetCode=HEALTH_REAC (accessed 6 July 2017).

25. Nivel: Primary Care in Europe. https://www.nivel.nl/en/primary-care (accessed 6 July 2017).

26. Soler JK, Yaman H, Esteva M, et al. Burnout in European family doctors: the EGPRN study. Fam Pract 2008;25:245-65.

27. van den Berg MJ, van Loenen T, Westert GP. Accessible and continuous primary care may help reduce rates of emergency department use. An international survey in 34 countries. Fam Pract 2016;33:42-50.

28. Osborn R, Moulds D, Schneider EC, et al. Primary Care Physicians In Ten Countries Report Challenges Caring For Patients With Complex Health Needs. Health Aff 2015;34:2104-12.

29. Eurobarometer. http://www.gesis.org/eurobarometer-data-service/ home/ (accessed 6 July 2017).

30. Hobbs FDR, Bankhead C, Mukhtar T, et al. Clinical workload in UK primary care: a retrospective analysis of 100 million consultations in England, 2007-14. Lancet 2016;387:2323-30.

31. Nizami S, Khan I, Bhutta Z. Paediatric prescribing in Karachi. J Pak Med Assoc 1997.

32. Jin G, Zhao Y, Chen C, et al. The length and content of general practice consultation in two Urban districts of Beijing: a preliminary observation study. PLoS One 2015;10:e0135121.

33. Guyon AB, Barman A, Ahmed JU, et al. A baseline survey on use of drugs at the primary health care level in Bangladesh *. Bull World Health Organ 1994;72:265-71.

34. Nizami SQ, Khan IA, Bhutta ZA. Drug prescribing practices of general practitioners and paediatricians for childhood diarrhoea in Karachi, Pakistan. Soc Sci Med 1996;42:1133-9.

35. Reeve J, Dowrick CF, Freeman GK, et al. Examining the practice of generalist expertise: a qualitative study identifying constraints and solutions. JRSM Short Rep 2013;4:204253331351015.

36. ISRCTN - ISRCTN34092919: Living well with multiple morbidity.

37. Collings J. General practice in ENGLAND today -a reconnaissance. Lancet 1950;255:555.

38. Irving G, Reeve J. Do GPs really provide 47 minutes a year for the patient? Br J Gen Pract 2012;62:404-5.

39. Saunders CL, Elliott MN, Lyratzopoulos G, et al. Beyond the ecological fallacy: potential problems when studying healthcare organisations. J R Soc Med 2016;109:92-7.

40. Australian GP Statistics and Classification Centre. General practice activity in Australia 2006-07, 2006.

41. NAMCS/NHAMCS - About the Ambulatory Health Care Surveys. https://www.cdc.gov/nchs/ahcd/index.htm (accessed 6 July 2017).

42. Afghanistan Medicine Use Study: A Survey of 28 Health Facilities in 5 Provinces, 2009.

43. Britt $\mathrm{H}$, Valenti L, Miller $\mathrm{G}$. Time for care. Length of general practice consultations in Australia. Aust Fam Physician 2002;31:876-80.

44. Health Information Directorate. Health Statistics 2007. Bahrain: Arabian Printing Press, 2007.

45. Hogerzeil HV, Bimo, Ross-Degnan D, et al. Field tests for rational drug use in twelve developing countries. Lancet 1993;342:1408-10.

46. Ahmed SM, Islam QS. Availability and rational use of drugs in primary healthcare facilities following the National drug policy of 1982: is Bangladesh on right track? J Health Popul Nutr 2012;30:99-108.

47. Alamgir $\mathrm{H}$, Ahmed M. Studies on Drug Use Pattern and Cost Efficiency in Upozila Health Complexes in Dhaka Division of Bangladesh. Am Sci Res J ... 2015.

48. Deveugele M, Derese A. Consultation length in general practice: cross sectional study in six European countries. BMJ 2002;325:472.

49. INAMI/RIZIV. Register van de huisartsen: aantal en profiel van de huisartsen in 2005, 2005

50. dos SV, Nitrini S. Indicadores do uso de medicamentos prescritos e de assistência ao paciente de serviços de saúde. Rev Saude Publica 2004;38:819-34.

51. Lopes AEC, Teixeira ACA, Gurgel MLF MM. Drug use of evaluation in health services in Fortaleza, Brasil. INRUD 1996;6.
52. Cunha M, Zorzatto J, Castro L. Avaliação do uso de medicamentos na Rede Pública Municipal de Saúde de Campo Grande/MS, 2002.

53. Portela A, Silva PCDda, Simões MOdaS, et al. Indicadores de prescrição e de cuidado ao paciente na atenção básica do município de Esperança, Paraíba, 2007. Epidemiol e Serviços Saúde 2012;21:341-50.

54. Marcondes NSP. A assistência farmacêutica básica e o uso de medicamentos na zona urbana do município de Ponta Grosssa. Paraná: estudo de caso, 2002.

55. Kringos DS, Boerma WGW, Spaan E, et al. Evaluation of the organizational model of primary care in Turkey: a survey-based pilot project in two provinces of Turkey. 2008 http://www.narcis.nl/ publication/RecordID/publicat\%3A1001602

56. Chareonkul C, Khun VL, Boonshuyar C. Rational drug use in Cambodia: Study of three pilot health centers in Kampong Thom province. Southeast Asian J Trop Med Public Health 2002:33:418-24.

57. Wolfe S, Badgley RF, Kasius RV, et al. The work of a group of doctors in Saskatchewan. Milbank Mem Fund Q 1968;46:103-29.

58. Collyer JA. A Family Doctor's Time. Can Fam physician Médecin Fam Can 1969;15:63-9.

59. Stewart M, Brown JB, Weston WW. Patient-Centred Interviewing Part III: Five Provocative Questions. Can Fam physician Médecin Fam Can 1989;35:159-61.

60. Ugalde A, Homedes N. Estudio de consulta externa en Costa Rica. Development Technologies, San José, Costa Rica 1988;1988.

61. Ozvacić Adzić Z, Katić M, Kern J, et al. Patient, physician, and practice characteristics related to patient enablement in general practice in Croatia: cross-sectional survey study. Croat Med $J$ 2008;49:813-23.

62. Embaye A. Drug Use Studies in Eritrean Health Facilities, 1999.

63. Tähepõld H, Maaroos H, Kalda R, et al. Structure and duration of consultations in Estonian family practice. Scand J Prim Health Care 2009.

64. Mulugeta T, Angamo NTW. Assessment of patterns of drug use by using World Health Organization's Prescribing, patient care and health facility indicators in selected health facilities in Southwest Ethiopia. J Appl Pharm Sci 2011;1:62-6.

65. Desta Z, Abula T, Beyene L, et al. Assessment of rational drug use and prescribing in primary health care facilities in north west Ethiopia. East Afr Med J 1997;74:758-63.

66. Srikanth B. A prospective study on evaluation of use of drugs at prescriber, dispenser and patients level based on 'who' core drug. Editor board. https://www.researchgate.net/profile/ Akshaya_Bhagavathula/publication/254559382_A_PROSPECT IVE_STUDY_ON_EVALUATION_OF_USE_OF_DRUGS_AT_P RESCRIBER_DISPENSER_AND_PATIENTS_LEVEL_BASED_ON_ WHO_CORE_DRUG_USE_INDICATORS_IN_ETHIOPIA/links/ 0046351fcf7ade2310000000.p

67. Kuusela M, Vainiomäki P, Kiviranta A, et al. The Missing Evaluation at the End of GP's Consultation. Int J Family Med 2013;2013:1-6.

68. Breuil-Genier PGC. La durée des séances des médecins généralistes. Etudes Result 2006:481-8.

69. Fry J. Hong Kong: Need for improvement in primary care. Lancet 1990;336:558.

70. Sharma J, Kataria M, Gandhi H. Quality of medical care by central government health scheme-a study. Heal Popul 1978 http:// europepmc.org/abstract/med/10247249

71. Sarwal R. Reforming Central Government Health Scheme into a 'Universal Health Coverage'model. Natl Med J INDIA 2015.

72. Roy Chaudhury R, et al. Quality medicines for the poor: experience of the Delhi programme on rational use of drugs. Health Policy Plan 2005;20:124-36.

73. Promoting rational use of drugs in indonesia.

74. Khori V, Changizi S, Biuckians E, et al. Relationship between consultation length and rational prescribing of drugs in Gorgan City, Islamic Republic of Iran. EMHJ 2012;18:480-6.

75. Omer W. Use of mobile phones to calculate consultation time and comparing with perceived time in private clinics in erbil city, Iraq. 141st APHA Annual Meeting and Exposition (November 2 November 6, 2013): APHA, 2013.

76. Vinker S, Nathan T. Annual accumulated duration of time of primary care visits and its association in preventive medicine: A crosssectional study.

77. Ohtaki S, Ohtaki T, Fetters MD. Doctor-patient communication: a comparison of the USA and Japan. Fam Pract 2003;20:276-82.

78. Wooldridge AN, Arató N, Sen A, et al. Truth or fallacy? Three hour wait for three minutes with the doctor: Findings from a private clinic in rural Japan. Asia Pac Fam Med 2010;9:11.

79. Mochizuki A. Conference proceeding of The 3rd JPCA academic conference:258. 
80. Evaluation of Drug Use in Jordan Using WHO Patient Care and Health Facility Indicators.

81. Performance of health providers in primary health care services in Jordan, 2004

82. Awad A, Al-Saffar N. Evaluation of drug use practices at primary healthcare centers of Kuwait. Eur J Clin Pharmacol 2010.

83. Institution T personal health care. Year analysis of patients state fund of Vilnius Zone 2008.

84. Sosola A. An assessment of prescribing and dispensing practices in public health facilities of southern Malawi, 2007.

85. Sciortino P. A service profile of maltese general practitioners. A provider survey of the general practice component of the Maltese Health Care system 2002.

86. Dahal P, Bhattarai B, Adhikari D, et al. Drug use pattern in Primary Health Care facilities of Kaski District, Western Nepal. Sunsari Tech 2013;1:1-8 http://www.nepjol.info/index.php/STCJ/article/view/ 8652

87. Van den Berg MJ, Kolthof ED. De Bakker DH V der ZJ. Second Dutch National Study of diseases and procedurs in general practice. The workload of general practitioners 2004.

88. Baker AS. What do New Zealand general practitioners do in their offices? N Z Med J 1976;83:187-90.

89. Chedi B. Drug use pattern in out-patient children: a comparison between primary and secondary health care facilities in Northern Nigeria. Afr J Pharm Pharmacol 2015;9:74-81.

90. Mjell J. Pasientene tror vi har god tid. Utposten 1989;4:182-3.

91. Gadgil ME. Average consultation length per GP. Norway, 2009.

92. Thaver I. Prescribing patterns of primary care providers in squatter areas of Karachi. JOURNAL-PAKISTAN Med Assoc 1995.

93. Perú (AMF 2015). Ser médico de familia en. http://amf-semfyc.com/ web/article ver.php?id=1497

94. Pawlikowska TRB, Walker JJ, Nowak PR, et al. Patient involvement in assessing consultation quality: a quantitative study of the Patient Enablement Instrument in Poland. Health Expect 2010;13:13-23.

95. Nogueira JD. Duração da Consulta: Perspectivas dos Médicos e dos Pacientes, 2002, 2002.

96. Granja M, Ponte C, Cavadas LF. What keeps family physicians busy in Portugal? A multicentre observational study of work other than direct patient contacts. BMJ Open 2014;4:e005026.

97. Bener A, Almarri S, Ali B, et al. Do minutes count for health care? Consultation length in a tertiary care teaching hospital and in general practice. Middle East J Fam 2007 http://www.mejfm.com/ journal/Jan2007/MEJFM_Jan2007.pdf\#page=3

98. Tehepold H. Patient consultation in family medicine. Dissertation of the degree of doctor of medical sciences 2006.

99. Evaluation of the organizational model of primary care in the Russian Federation. 2014

100. Al-Shammari SAI. Factors associated with consultation Time in Riyad Primary Health Care Centres, Saudi Arabia. Saudi Med J 1991:12:371-5.

101. James $\mathrm{E}$, Assawaf $\mathrm{K}$, Zarie $\mathrm{AH}$, et al. Factors influencing rational drug use in primary health care centres in Qassim region, Saudi Arabia. Saudi Pharm J 2003;11:126-35.

102. El Mahalli AA, Oam A, Al-Dawood SF, et al. WHO/INRUD patient care and facility-specific drug use indicators at primary health care centres in Eastern province, Saudi Arabia. East Mediterr Heal $\mathrm{J}=$ La Rev sante la Mediterr Orient = al-Majallah al-s.ih.h.iyah li-sharq al-mutawassit 2012;18:1086-90.

103. Al-Abbad H. Gender Differences in Consultation Time and its Relation to Patient's Satisfaction: a cross-sectional study at King Khalid University Primary Health Care Clinics. From Ed 2015.

104. Balbaid O, Al-Dawood K. Factors associated with patient's care during consultation in ministry of health facilities, Jeddah city, Saudi Arabia. J Fam community 1997 http://www.ncbi.nlm.nih.gov/pmc/ articles/PMC3437133/

105. Stojanović B, Janković S. An analysis of drug use indicators within primary care health facilities in Jagodina. Medicus 2002.

106. Voo YO. Consultation length and case mix in a general practice clinic. Singapore Med J 1999:40:13-17.

107. Švab I, Petek Šter M, Kersnik J, et al. Cross sectional study of performance of Slovene General practitioners. Zdr var 2005:44:183-92.

108. Petek Ster M, Svab I, Zivcec Kalan G. Factors related to consultation time: experience in Slovenia. Scand J Prim Health Care 2008;26:29-34.
109. Hart JT. Primary medical care in Spain. Br J Gen Pract 1990;40:255-8.

110. P U, I. G. Estudio sobre el uso de los medicamentos en un área de salud por medio de una encuesta. Ars Pharm 2001;42:185-202.

111. Rational Use of Medicine Pratical Work Paper - Documents.

112. Andersson SO, Mattsson B. Length of consultations in general practice in Sweden: views of doctors and patients. Fam Pract 1989;6:130-4.

113. inrud news. INRUD News, 1992:3:3

114. Nsimba SED. Assessing prescribing and patient care indicators for children under five years old with malaria and other disease conditions in public primary health care facilities. Southeast Asian $J$ Trop Med Public Health 2006;37:206-14.

115. Kringos DS, Boerma WGW, Spaan E, et al. A snapshot of the organization and provision of primary care in Turkey. BMC Health Serv Res 2011;11:90.

116. Sensoy N. A Research on Patient Satisfaction with Primary Health Care in the Center of Afyonkarahisar. J Clin Anal Med 2014;5:29-34.

117. Eczacının Sesi: Pratisyen Hekimlerin Reçete Yazımını Şekillendiren Faktörler.

118. Minstry of Health. Annual Health Report, Ministry of Health,. Abu Dhabi, United Arab Emirates 2004.

119. Ah A. Consultation Length in Primary Health Care: Is It Getting Longer? Amani Al Hajeri.

120. Abdul Rasool BK, Fahmy SA, Abu-Gharbieh EF, et al. Prácticas profesionales y percepción sobre el uso racional de medicamentos según la metodología de OMS en Emiratos Árabes Unidos. Pharm Pract:8:70-6.

121. Fry J. A year in General Practice: a study of morbidity. 1952;2:249-52.

122. Watt C. A year of General Practice. BMJ 1952;2:115-6

123. Mair A, Mair G. Facts of importance to the organisation of the national health service from a five year study of general practice. Bmj 1959;1:281-4.

124. Crombie DL, Cross KW. The work-load in general practice. Lancet 1964;2:354-6 http://www.ncbi.nlm.nih.gov/pubmed/14172341

125. Morrell DC. Expressions of morbidity in general practice. Br Med J $1971 ; 2: 454-8$

126. Scottish Home and Health Department. The study of consultations in general practice: Scottish health service statistics. 1973;27.

127. Hughes D. Consultation length and outcome in two group general practices. J R Coll Gen Pract 1983;33:143-7.

128. Wilkin $\mathrm{D}$, Metcalfe $\mathrm{DH}$. List size and patient contact in general medical practice. Br Med J 1984;289:1501-5.

129. Department of Health and Social Security. General medical practitioners' workload. A report prepared for the doctors' and dentists' review body. London 1985.

130. Peter L, Tate JB, Catchpole PJ. Practice activity analysis: collaboration between general practitioners and a family practitioner committee. J R Coll Gen Pract 1989;39:297-9.

131. Ogden J, Bavalia K, Bull M, et al. "I want more time with my doctor": a quantitative study of time and the consultation. Fam Pract 2004;21:479-83.

132. HSCIC. 2006/2007 GP workload survey, 2007.

133. Bwera A, Lamunu M. Survey of essential drug use in Rakai district Uganda, June, 1996. J Clin 1997 https://scholar.google.co.uk/ scholar?start=60\&q=INRUD+AND+\%22consultation+time $\% 22+$ OR+\%22+consultation+length $\% 22+\& h l=e n \& a s \_s d t=0,5 \# 0$

134. Marvel MK, Epstein RM, Flowers K, et al. Soliciting the Patient's Agenda. JAMA 1999;281:283.

135. Rhoades DR, McFarland KF, Finch WH, et al. Speaking and interruptions during primary care office visits. Fam Med;33:528-32.

136. Blankfield RP, Goodwin M, Jaén CR, et al. Addressing the unique challenges of inner-city practice: a direct observation study of inner-city, rural, and suburban family practices. J Urban Health 2002;79:173-85.

137. Prescriptionpatternsf O. Micky Ndhlovu, 2009.http://146.141.12.21/ handle/10539/8006

138. Public sector survey 2000. Harare, Directorate of Pharmacy Services Ministry of Health and Child Welfare. Zimbabwe 2000.

139. Trap B, Hansen E, Hogerzeil H. Prescription habits of dispensing and non-dispensing doctors in Zimbabwe. Health Policy Plan 2002. 